\title{
Brasil y los Países Ribereños de la Cuenca del Caribe: Prolegómenos para un Nuevo Entendimiento en los Primeros Años del Siglo XXI
}

\author{
Carlos Federico Domínguez Avila*
}

Resumen: El artículo aborda las relaciones económicas, políticas y de seguridad internacional vigentes entre el Brasil y los 25 países de la cuenca del Caribe - quiere decir, México, Centroamérica, las Antillas, Colombia, Venezuela, Guyana y Surinam; además de una decena de territorios coloniales administrados por potencias extra-regionales. Constatase que las relaciones económicas son muy intensas, especialmente en términos comerciales y recientemente de inversiones productivas. Al final del artículo se proponen y analizan tres escenarios para el futuro de las relaciones brasileño-caribeñas.

Palabras-clave: Brasil, Gran Caribe, Economía Internacional, Política Internacional, Seguridad Internacional.

Abstract: This paper explores the economic, political and security relations between Brazil and the 25 Caribbean countries - Mexico, Central America, the Caribbean islands, Colombia, Venezuela, Guiana and Suriname, inasmuch the colonial territories. The results show that the economic relations are very intensive among the countries analyzed, specially pertinent to trade and investment. At the last part, we consider and analyze three scenarios for the Brazilian-Caribbean future relations.

Keywords: Brazil, Caribbean Basin, International Economics, International Politics, International Security.

\footnotetext{
* Doctor en Historia de las Relaciones Internacionales por la Universidad de Brasilia, profesor e investigador de UNIEURO e IESB (ambas en Brasilia). E-mail: cdominguez_unieuro@yahoo.com.br. Recebido em 13/01/08 e aceito em 02/06/08.
} 


\section{Introducción}

A lo largo de muchos años, Brasil y los 25 países ribereños de la cuenca del Caribe lograron construir relaciones correctas, cooperativas y pacíficas, aunque también de baja intensidad, modestas y, en ciertos aspectos, irrelevantes. En general, los países priorizaron sus relaciones con otros actores internacionales y terminaron adoptando una actitud negligente para su agenda recíproca. En los primeros años del siglo XXI, la tendencia histórica de relaciones correctas pero de baja intensidad comenzó a cambiar, observándose una creciente convergencia, afinidad y solidaridad. Conviene destacarse de ahora que las nociones Gran Caribe o cuenca del Caribe tienen antecedentes bastante antiguos. Ambas incluyen a todos los países ribereños del Mar Caribe, esto es, el archipiélago de las Antillas (Cuba, Jamaica, Barbados, etc.), México, los países del istmo centroamericano, Colombia, Venezuela, Guyana, y Surinam, bien como a una decena de territorios coloniales.

Actualmente las relaciones económicas entre las partes son sumamente significativas y cada vez más intensas. Así, por ejemplo, según estadísticas del gobierno brasileño, en 2007 el valor de las exportaciones brasileñas con destino a los países del Gran Caribe superó los US\$ 16 mil millones. Por lo tanto, los países de la cuenca del Caribe se erigieron, conjuntamente, en uno de los más importantes destinos para las exportaciones brasileñas en el mundo. Naturalmente, ello es algo sumamente relevante y sugestivo. En el campo político, el diálogo bilateral y multilateral también es cada vez más intenso y fecundo.

\section{Fundamentos económicos}

Las relaciones económicas vigentes entre Brasil y los países de la cuenca del Caribe incluyen principalmente flujos comerciales y recientemente inversiones productivas en ambos sentidos. También se incluyen aspectos de cooperación técnica horizontal y de transferencia de tecnología. Conviene agregar que tales relaciones son influenciadas por las transformaciones globales y hemisféricas, cuyas tendencias son favorables a una creciente interdependencia, liberalización comercial y cooperación entre países en desarrollo (HELD et al., 1999; CEPAL, 2002). 


\section{Comercio}

El comercio Brasil-Gran Caribe ha sido muy dinámico en los primeros años del siglo XXI. Según estadísticas de comercio publicadas por el Ministério de Desenvolvimento, Indústria e Comércio Exterior, el valor de las exportaciones brasileñas con destino a los países (y territorios coloniales) que forman parte del Gran Caribe creció de US\$ 4.2 mil millones en 2000 para US\$ 17 mil millones en 2007 - y seguramente se aproximará de los US\$ 18.5 mil millones en 2010. Entretanto, en el mismo período el valor de las importaciones brasileñas procedentes de aquellos países aumentó de US\$2.7 mil millones a US\$ 3.8 millardos - con una estimación de 4.5 mil millones de dólares en 2010. Consecuentemente, la balanza comercial general vigente es claramente favorable para el lado brasileño (ver Cuadro 1). ${ }^{1}$

${ }^{1}$ CANTANHÊDE, Eliade. O Caribe na rota da política externa. Folha de São Paulo, 10.5.2006. Disponible em: http://wwwl.folha.uol.com.br/folha/pensata/ult681u209.shtml. Acesso em: 15 marzo 2006. 
Cuadro 1 - Tendencias de comercio Brasil-Gran Caribe, 2000 y 2010

(Millones de US\$ FOB)

\begin{tabular}{|c|c|c|c|c|c|c|}
\hline & \multicolumn{3}{|c|}{ Exportaciones brasileńas con destino a: } & \multicolumn{3}{|c|}{ Importaciones brasileńas procedentes de: } \\
\hline & 2000 & 2007 & $2010^{*}$ & 2000 & 2007 & $2010^{*}$ \\
\hline México & 1.711 & 4.260 & 4.593 & 755 & 1.979 & 2.346 \\
\hline Colombia & 515 & 2.339 & 2.943 & 415 & 427 & 489 \\
\hline Venezuela & 751 & 4.723 & 5.424 & 1.328 & 346 & 538 \\
\hline Cuba & 95 & 324 & 562 & 21 & 89 & 106 \\
\hline Haití & 17 & 76 & 34 & 0 & 0 & 1 \\
\hline República Dominicana & 132 & 459 & 643 & 2 & 13 & 19 \\
\hline Costa Rica & 119 & 482 & 628 & 30 & 155 & 163 \\
\hline El Salvador & 41 & 176 & 219 & 0 & 4 & 6 \\
\hline Guatemala & 76 & 256 & 312 & 1 & 12 & 16 \\
\hline Honduras & 31 & 131 & 189 & 0 & 5 & 8 \\
\hline Nicaragua & 9 & 55 & 86 & 0 & 0 & 2 \\
\hline Panamá & 82 & 383 & 429 & 16 & 17 & 24 \\
\hline Antigua e Barbuda & 1 & 6 & 7 & 0 & 0 & 1 \\
\hline Bahamas & 27 & 300 & 149 & 1 & 3 & 5 \\
\hline Barbados & 16 & 21 & 31 & 7 & 32 & 24 \\
\hline Belice & 2 & 4 & 5 & 0 & 0 & 1 \\
\hline Dominica & 1 & 2 & 2 & 0 & 0 & 0 \\
\hline Granada & 1 & 6 & 7 & 0 & 0 & 1 \\
\hline Guyana & 5 & 18 & 24 & 0 & 2 & 5 \\
\hline Jamaica & 40 & 247 & 317 & 1 & 4 & 5 \\
\hline Santa Lucia & 51 & 1.035 & 58 & 0 & 0 & 0 \\
\hline S. Cristobal y Nevis & 0 & 0 & 5 & 0 & 0 & 0 \\
\hline S. Vicente y Granadinas & 1 & 3 & 5 & 0 & 0 & 0 \\
\hline Surinam & 7 & 37 & 59 & 0 & 19 & 31 \\
\hline Trinidad e Tobago & 93 & 690 & 752 & 44 & 113 & 169 \\
\hline Puerto Rico (EUA) & 185 & 248 & 341 & 138 & 165 & 195 \\
\hline Islas Caimán (GB) & 101 & 20 & 74 & 8 & 137 & 183 \\
\hline Antillas Holandesas & 84 & 830 & 356 & 20 & 8 & 18 \\
\hline Aruba $(\mathrm{H})$ & 4 & 75 & 103 & 26 & 272 & 159 \\
\hline Guadalupe (Fr) & 43 & 23 & 37 & 0 & 0 & 1 \\
\hline Guyana Francesa & 3 & 8 & 15 & 0 & 0 & 1 \\
\hline Martinica (Fr) & 8 & 26 & 31 & 0 & 0 & 1 \\
\hline Islas Vírgenes (EUA) & 14 & 22 & 27 & 0 & 3 & 6 \\
\hline Islas Vírgenes (GB) & 6 & 29 & 34 & 7 & 14 & 26 \\
\hline Otros caribeńos** & 4 & 20 & 24 & 0 & 5 & 7 \\
\hline Total & 4.275 & 17.354 & 18.525 & 2,720 & 3.824 & 4.547 \\
\hline
\end{tabular}

FUENTE: Ministério de Desenvolvimento, Indústria e Comércio Exterior do Brasil (Disponible em: http://aliceweb.desenvolvimento.gov.br. Consulta en: 12 de junio de 2008.

* Estimaciones para el año de 2010. ${ }^{* *}$ Estimaciones para otros caribeńos incluye territorios coloniales. "0" Representa menos de un millón de dólares. 
En la pauta de las exportaciones brasileñas para el mercado del Gran Caribe sobresalen bienes de mediana y alta tecnología, sobretodo de los sectores automotriz (y aéreo), químico, plásticos, electro-electrónicos, metalmecánica, material médico-quirúrgico, maquinaria agropecuaria, fertilizantes, material de escritorio, juguetes, y papel. Alimentos, particularmente soya, así como ciertas semillas, maderas y aceites, también forman parte de las exportaciones brasileñas con destino hacia aquellos países, territorios y comunidades. Se trata, en general, de bienes de capital y de consumo duradero, de buena calidad y con precios competitivos. Cabe mencionar que en su esfuerzo por penetrar y consolidarse en el mercado caribeño los exportadores brasileños gozan del eficiente apoyo de la Agência de Promoção de Exportação e Investimentos (APEX-Brasil). ${ }^{2}$

Las importaciones brasileñas procedentes de países del Caribe incluyen petróleo y derivados (Venezuela y México), productos de media y alta tecnología (especialmente informática procedente de México y Costa Rica, o bien reexportados desde islas anglófonas y Panamá), automóviles y repuestos (México), remedios y biotecnología (Cuba), entre muchos otros.

El creciente déficit comercial de los caribeños con relación al Brasil precisa ser acompañado y evaluado periódicamente por los gobiernos y por las empresas de comercio exterior, procurando evitar una situación de desequilibrio estructural y eventual inconformidad de las partes - lo que podría provocar algún tipo de neo-proteccionismo. Trabajar para reducir el notorio déficit comercial de los países caribeños es vital para lograr una relación justa, correcta y mutuamente ventajosa. El propio Presidente Luiz Inácio Lula da Silva, al evaluar la relación comercial brasileño-guatemalteca en 2005, reconoció el problema y manifestó - por ejemplo - que: "para mi gobierno, la relación comercial buena es aquella que es de una calle de dos sentidos, en que podamos vender, pero que podamos comprar para tornar el comercio algo más equilibrado y más substancial para los dos países."3

\footnotetext{
${ }^{2}$ Ministério de Desenvolvimento, Indústria e Comércio Exterior. Brasil Exportador, Sistema AliceWeb. Disponível em: http://aliceweb.desenvolvimento.gov.br. Acesso em: 6 junio 2008.

3 "Declaração à imprensa do Presidente da República, Luiz Inácio Lula da Silva, por ocasião da visita do Presidente da República da Guatemala, Oscar Berger”. Ministério das Relações Exteriores, Brasilia, 10.03.2006. Disponível em: http://www.mre.gov.br. Acesso em: 15 marzo 2007.
} 
Conviene agregar que algunos países de la cuenca del Gran Caribe -tales como México, Colombia, Venezuela y Cuba - forman parte, conjuntamente con Brasil, de la Asociación Latinoamericana de Integración (ALADI). En el marco de este proceso de integración económica, el comercio bilateral entre las partes es regulado por los llamados Acuerdos de Complementación Económica. El Acuerdo de Complementación Económica número 53 del sector automotriz negociado entre el Brasil y México es un importante ejemplo de este tipo de instrumentos a disposición de los países, recordando que el mismo procura un desarrollo comercial equilibrado, saludable y mutuamente ventajoso para las partes.

Por último, vale recordar que los gobiernos de Venezuela, Cuba y México solicitaron una incorporación plena y/o una asociación al MERCOSUR siendo que el primer país fue aceptado a partir de 2006, restando únicamente la ratificación parlamentaria correspondiente. Más aún, existen negociaciones paralelas para una aproximación entre el MERCOSUR y los países del Sistema de Integración Centroamericano (SICA) y de la Comunidad Caribeña (CARICOM).

\section{Inversiones productivas}

Las inversiones productivas de capitales privados forman parte de la agenda económica vigente entre Brasil y los países del Gran Caribe. Las inversiones de capitales mexicanos en el mercado brasileño son especialmente importantes, y superan los US\$ 3 mil millones. ${ }^{4}$ Las inversiones productivas mexicanas incluyen al sector de las comunicaciones (Claro), turismo (Grupo Posadas) y alimentos (Bimbo, Jugos del Valle). Así, México es una importante fuente de inversiones extranjeras directas en Brasil.

Las inversiones productivas de empresas brasileñas en la cuenca del Caribe son relativamente recientes. Actualmente existen iniciativas cada vez más relevantes de capitales privados brasileños que procuran operar en los países caribeños pretendiendo satisfacer la demanda reprimida local y, sobretodo, aprovechar los acuerdos de libre comercio existentes entre ciertos países de la región y los Estados Unidos -ello ha sido particularmente evidente en el

\footnotetext{
${ }^{4}$ Según las estadísticas mexicanas, el monto total de las inversiones de aquel país en la economía brasileña superarían los diez mil millones de dólares.
} 
caso del sector textil brasileño con relación a los tratados de libre comercio vigentes entre Estados Unidos y México (ALCAN/NAFTA) y entre Estados Unidos y Centroamérica (CAFTA). Efectivamente, reconocidas empresas brasileñas, tales como Santista Têxtil, iniciaron en los últimos meses ambiciosos proyectos de inversiones en la región, especialmente en Honduras y República Dominicana. ${ }^{5}$ En el fondo se trata de utilizar los países caribeños como virtuales plataformas de exportación, gozando de preferencias arancelarias pactadas con mercados más expresivos (DOMÍNGUEZ AVILA, 2006).

La creciente participación de empresas constructoras brasileñas en los principales proyectos de infraestructura económica de los países de la cuenca del Caribe también forma parte de la agenda vigente. Conviene tener presente que actualmente en el Gran Caribe existen ciertos proyectos de infraestructura económica de interés regional, hemisférico y global, destacándose los casos de la ampliación del canal de Panamá, la construcción de un canal interoceánico alternativo en Nicaragua, la construcción y modernización de la infraestructura de transportes -carreteras, puertos, aeropuertos, etc.- en casi todos los países, sin olvidar proyectos hidroeléctricos, refinerías, de telecomunicaciones, gasoductos, entre otros - todos ellos financiados con recursos domésticos, bilaterales y principalmente multilaterales. Empresas de ingeniería brasileñas tales como Obedrecht, Andrade Gutierrez, Camargo Corrêa, Queiroz Galvão, Intertechne y Alusa, entre otras, ya demostraron interés en participar activamente de aquellos y otros proyectos. ${ }^{6}$

Cabe mencionar que algunos proyectos de comercio e inversiones vigentes entre Brasil y países del Gran Caribe gozan del apoyo financiero del gobierno brasileño, mediante líneas de créditos concedidas por el Banco Nacional de Desenvolvimento Econômico e Social (BNDES). En ese sentido se inspira, por ejemplo, el Programa de Incentivo aos Investimentos Brasileiros na América Central e Caribe (PIBAC), anunciado por el presidente Luiz Inácio Lula da Silva, en Guatemala, en septiembre de 2005. Resumidamente, el PIBAC procura incentivar las inversiones de capitales privados brasileños

\footnotetext{
${ }^{5}$ CAPELA, Mauricio. A roupa nova da Santista. Isto é Dinheiro, 19.1.2005. Disponível em: http://www.terra.com.br/ istoedinheiro/384/negocios/roupa_nova_santista.htm. Acesso em: 15 marzo 2007.

${ }^{6}$ BACOCINA, Denize. Lula confirma interesse brasileiro em ampliação do Canal do Panamá. BBC Brasil, 11 ago. 2007. Disponível em: www.bbc.co.uk/portuguese/reporterbbc/story/2007/08/070810_lulapanama_db_ac.shtml. Acesso em: 12 sept. 2007.
} 
en los países del Gran Caribe, sea para abastecer los mercados locales o para exportar desde ellos hacia terceros mercados. ${ }^{7}$

Al mismo tiempo, conviene agregar que los gobiernos de algunos países caribeños han demostrado interés en realizar inversiones conjuntas con empresas públicas brasileñas, sobretodo del sector de energía (petróleo y gas). En el caso de Venezuela, se trata de proyectos conjuntos entre las empresas estatales PDVSA y PETROBRAS, incluyendo la explotación de la Faja Petrolífera del Orinoco, la construcción de refinería binacional en el Estado de Pernambuco (nordeste del Brasil), y el Gasoducto del Sur (VenezuelaBrasil-Argentina). Los gobiernos de México, Cuba y Costa Rica también solicitaron apoyo e inversiones conjuntas, principalmente en lo concerniente a la exploración de recursos energéticos en aguas profundas - aprovechando la mundialmente reconocida tecnología brasileña en esa especialidad.

Las inversiones financieras de capitales privados brasileños, especialmente en paraísos fiscales - Islas Cayman, Panamá, Bahamas, Islas Vírgenes, y otras-, son de difícil cuantificación y de orígenes poco claros o francamente ilícitos. Aparentemente tales aplicaciones financieras son bastante significativas y superiores a los tres mil millones de dólares.

Por último, vale mencionar que muchos países caribeños mantienen una deuda bilateral pública con Brasil. En algunos casos, ciertos países fueron favorecidos por una condonación parcial o total de tales deudas concedidas por el gobierno brasileño. Ese fue el caso de Nicaragua, país que en 1998 recibió del gobierno brasileño una condonación de $95 \%$ de su deuda bilateral. Otros países han solicitado del gobierno brasileño un tratamiento semejante, sea en términos estrictamente bilaterales o en el marco de organismos financieros internacionales (BID y otros), donde el peso de las opiniones brasileñas es altamente significativo.

\footnotetext{
${ }^{7}$ TOLEDO, Diego. Brasil lança programa para investimentos na América Central. BBC Brasil, 14 set. 2005. Disponível em: www.bbc.co.uk/portuguese/reporterbbc/story/2005/09/050914_diegoguatemalacg.shtml. Acesso em: 5 enero 2006.
} 


\section{Cooperación técnica horizontal para el desarrollo y transferencia de tecnología}

La cooperación técnica horizontal entre países en desarrollo forma parte del diálogo vigente y de la solidaridad Sur-Sur, así como de la cooperación intrarregional vigente entre países de América Latina y el Caribe.

La cooperación técnica brasileña con los países de la cuenca del Caribe es sumamente significativa y se realiza fundamentalmente a través de tres vías institucionales: (a) por la Agencia Brasileira de Cooperaçáo adscrita a la Cancillería, (b) por instituciones autónomas y especializadas del gobierno tales como EMBRAPA, EMBRATUR, CNPq, IBAMA, FIOCRUZ, ESAF, universidades e institutos de investigación, entre otros, y (c) por instituciones no gubernamentales o del tercer sector.

Los programas de becas de postgrado en universidades brasileñas son de particular interés para profesionales procedentes de países del Gran Caribe. Algunas áreas prioritarias de estudios académicos de extranjeros en Brasil incluyen: desarrollo agropecuario, manejo del medio ambiente, desarrollo industrial, salud y saneamiento, educación, ciencia y tecnología, formación profesional, administración pública, comunicaciones y transportes, biotecnología y energías renovables.

Ciertos países de la cuenca del Caribe ofrecen cooperación técnica horizontal al Brasil. Ese es el caso de los programas de becas propuestos por los gobiernos de México, Cuba y Venezuela. El gobierno cubano se ha destacado, también, por el envío de misiones de médicos, pedagogos especializados en desarrollo comunitario y entrenadores de ciertas disciplinas deportivas. La loable labor de tales profesionales ha sido reconocida por las autoridades (federales, estatales y municipales) y principalmente por la población beneficiada.

Una variante del modelo de cooperación técnica horizontal es la transferencia de tecnología. Ejemplo de ello es la posibilidad de producir etanol de caña de azúcar con uso de la reconocida tecnología brasileña. Tales recursos energéticos permitirían abastecer los mercados locales y eventualmente mercados de terceros países. Nótese que en las dos cumbres Lula-Bush, realizadas en marzo de 2007, los gobiernos de ambos países concordaron en apoyar proyectos pilotos de producción de etanol en cuatro 
países caribeños: Haití, República Dominicana, San Cristóbal y Nevis, y El Salvador. ${ }^{8}$ Aunque la reacción de la mayoría de los gobiernos caribeños ha sido positiva para con la eventual transferencia de tecnología brasileña para la producción de etanol y otros biocombustibles, no se puede ignorar la crítica reacción de los gobiernos de Venezuela y de Cuba frente al pacto Lula-Bush.

\section{Fundamentos políticos}

En el terreno político, el diálogo entre el gobierno de Brasil y sus contrapartes de los países del Gran Caribe es cada vez más intenso, complejo y constructivo, aunque también existen algunas divergencias puntuales. En general, el diálogo político acontece en nivel bilateral, especialmente cuando se trata de los países más influyentes, ello incluye las relaciones brasileño-mexicanas, brasileño-venezolanas, brasileño-colombianas, y brasileño-cubanas. También existen canales multilaterales, tales como los foros de cancilleres Brasil-SICA y Brasil-CARICOM. Nótese que Brasil es miembro observador de los debates de la Asociación de Estados del Caribe (AEC), que incluye a todos los países de la región. Los países en cuestión también forman parte de foros globales, hemisféricos y regionales, entre otros: las Naciones Unidas, la Organización de los Estados Americanos, y el Mecanismo Permanente de Consulta y Concertación Política (o Grupo de Rio). Consecuentemente, los encuentros entre las autoridades políticas y diplomáticas brasileñas y gran caribeñas son bastante frecuentes y dinámicos, sea en cumbres de jefes de Estado o en reuniones ministeriales.

La agenda política vigente entre Brasil y los países del Gran Caribe incluye los siguientes temas generales ${ }^{9}$ :

\footnotetext{
${ }^{8}$ Memorando de Entendimento entre o Governo da República Federativa do Brasil e o Governo dos Estados Unidos da América para Avançar a Cooperação em Biocombustíveis. São Paulo, 9 marzo 2007. Disponível em: www.mre.gov.br. Acesso em: 12 dic. 2007.

${ }^{9}$ Las ponderaciones sobre tendencias de relaciones políticas son resultado del análisis documental de más de una decena de declaraciones conjuntas y otros instrumentos diplomáticos (bilaterales y multilaterales) firmados por representantes de los gobiernos de Brasil y de diferentes países del Caribe desde 2000. Tales documentos oficiales pueden ser consultados en el portal de la cancillería brasileña. Disponível em: http://www.mre.gov.br.
} 
- La preservación y fortalecimiento de la Democracia, reconociéndose que la consolidación definitiva de los valores, mecanismos e instituciones democráticas en el continente americano es objetivo común. Esto último en el marco de la Resolución 1080 o Declaración de Santiago de Chile (de 1991), donde los países miembros de la Organización de los Estados Americanos se comprometieron a acompañar y actuar colectivamente para proteger la democracia representativa y el régimen democrático interamericano. Cabe mencionar que, en lo que corresponde a la cuenca del Caribe, tal resolución fue citada en los casos de las crisis de gobernabilidad democrática imperantes en Haití (1991-1993 y 20042007), Guatemala (1993) y Venezuela (1992 y 2002). Actualmente, y con excepción del peculiar caso cubano, todos los países del Caribe están en proceso de consolidación democrática, con resultados bastante positivos - principalmente en los casos de Costa Rica y el Caribe anglófono. La cooperación brasileña en materia de consolidación democrática incluye la participación de observadores en procesos electorales y la transferencia de sistemas y tecnologías electorales, inclusive la famosa urna electrónica utilizada experimentalmente y con buenos resultados en diferentes países de la cuenca del Caribe.

- La promoción y protección de los Derechos Humanos, observándose que las partes están comprometidas a cumplir lo dispuesto en la Declaración Universal de los Derechos Humanos, en la Declaración Americana de los Derechos y Deberes del Hombre y en la Convención Americana sobre Derechos Humanos, además de declaraciones específicas sobre protección de los derechos de las mujeres, de las comunidades indígenas, de las personas en riesgo social, y de las minorías. Los gobiernos del Brasil y de los países caribeños se han manifestado reiteradamente contra todas las formas de discriminación, intolerancia, racismo y xenofobia. Un tema de particular atención de los gobiernos y pueblos en cuestión está vinculado a la migración internacional, particularmente al respeto de los derechos humanos de las diásporas brasileñas y caribeñas residentes en los Estados Unidos y Canadá.

- La superación de la pobreza y la exclusión social, destacándose que las partes concuerdan en la necesidad urgente, global y objetiva de erradicar 
gradualmente tales problemas sociales que muchas veces son verdaderas amenazas para la gobernabilidad democrática en diferentes países. El caso haitiano es uno de los más elocuentes en ese sentido.

- La protección del Medio Ambiente y la promoción del Desarrollo Sustentable, reacuérdese que Brasil y los países del Gran Caribe son importantes actores con vínculos e intereses en la temática ambiental global, hemisférica y regional. En ese sentido, las partes frecuentemente concuerdan en la relevancia de aplicar los principios y compromisos asumidos en la Conferencia de las Naciones Unidas sobre Medio Ambiente y Desarrollo - o Conferencia de Rio de Janeiro (de 1992) - y pactos subsiguientes. La cooperación y coordinación Brasil-Gran Caribe en materia de desarrollo sustentable precisa ser ampliada y profundizada, inclusive porque los países en cuestión sufren las consecuencias de las transformaciones climáticas globales, quiere decir, procesos de desertificación, deforestación, perdida de recursos naturales no renovables, biopiratería, huracanes cada vez más violentos (por ejemplo: Katrina, Stan, Mitch, etc.), entre otros fenómenos.

- La manutención de la paz y de la seguridad internacional, en este punto normalmente las partes reiteran la necesidad de respetar y adscribir sus respectivas políticas internacionales a los principios centrales del Derecho Internacional, esto es, la libre determinación de los pueblos, la no intervención en los asuntos internos de otros Estados, la solución pacífica de las controversias, la proscripción de la amenaza o del uso de la fuerza, la defensa de los derechos humanos universalmente reconocidos, la cooperación internacional para el desarrollo, la igualdad jurídica entre los Estados, el respeto por las fronteras y tratados, entre otros. Las partes también concuerdan en la relevancia de evitar conflictos interestatales y en la necesidad de mantenerse como una ejemplar zona de paz y cooperación. La lucha conjunta y coordinada contra los ilícitos transnacionales forma parte de ésta temática, ello incluye la lucha contra la corrupción, el narcotráfico, el terrorismo, el tráfico de personas y otros seres vivos (animales y plantas), el tráfico de armas, y otros delitos conexos.

- El perfeccionamiento de los mecanismos de integración y coordinación regional y global, normalmente las partes concuerdan en la necesidad 
de profundizar los vínculos económicos intrarregionales con base en los criterios del regionalismo abierto, del comercio justo y de la integración regional. También, las partes toman nota de la necesidad de reformar gradualmente el sistema multilateral de comercio, procurando intercambios no discriminatorios, abiertos, transparentes, libres de proteccionismos, de subsidios ilegítimos y de unilateralismos. Este tópico también incluye la coordinación regional en foros globales donde se favorece el multilateralismo y se confirma la necesidad de oponerse a las prácticas unilateralistas y hegemónicas de ciertas potencias. Asimismo, normalmente las partes concuerdan en la necesidad de impulsar reformas en foros internacionales tales como la Organización de las Naciones Unidas y la Organización de los Estados Americanos. Un tema crucial y de crecientes divergencias particularmente entre los gobiernos de Brasil y de México es la posibilidad acceder a un puesto permanente en una eventual reforma del Consejo de Seguridad de la ONU. Aunque los gobiernos ambos países concuerdan en la necesidad de corregir los desequilibrios y distorsiones actuales, de ampliar su composición, de mejorar los mecanismos de toma de decisiones y de otorgar mayor transparencia y legitimidad, una eventual representación permanente latinoamericana y caribeña en el Consejo de Seguridad ha sido objeto de innúmeros debates y pocos consensos (FERNÁNDEZ, LIMA, 2005).

La agenda política Brasil-Gran Caribe también incluye la participación de actores no estatales tales como: partidos políticos, empresas transnacionales, organizaciones no gubernamentales, organizaciones profesionales, sindicales y campesinas, instituciones religiosas, guerrillas y otras fuerzas irregulares, entre otros. Los contactos entre actores no estatales brasileños y caribeños son cada vez más importante en la medida en que se erigen en virtuales grupos de presión junto a los respectivos gobiernos y sociedades. A esto último deben agregarse los crecientes vínculos socioculturales entre las partes. De un lado, se destaca la difusión cultural brasileña en el Gran Caribe mediante las acciones de los Centros de Estudios Brasileños (CEB's), adscritos a las representaciones diplomáticas del país sudamericano. Tales instituciones facilitan el conocimiento de la lengua portuguesa, de la literatura, de la 
música, de las artes plásticas, del folklore, de la gastronomía y de muchas otras expresiones culturales brasileñas - sin olvidarse de la popularidad en el Caribe de las telenovelas y el deporte brasileño. En contrapartida, la creciente relevancia de la cultura pan-hispánica en Brasil ayuda indirectamente a difundir aspectos positivos de la cultura gran caribeña en dicho país, con resultados bastante positivos y promisorios.

Por último, vale recordar que potencias extra-regionales con vínculos e intereses tanto en Brasil como en la cuenca del Caribe inciden directa o indirectamente en el dialogo y en la agenda política en cuestión. Entre tales actores extra-regionales conviene citar los casos de los Estados Unidos, Canadá, España, Chile, Gran Bretaña, Francia, Alemania, Holanda, Japón, Taiwán, Corea del Sur y, recientemente, China, Argentina, India, Suecia, Rusia, Italia, Filipinas, Israel y Sudáfrica. Nótese que algunas de esas potencias extra-regionales poseen colonias y/o territorios más o menos autónomos en la cuenca del Caribe, lo que conlleva el debate de la descolonización, de la autodeterminación de los pueblos, de la soberanía y de la proliferación de Estados.

\section{Fundamentos geopolíticos y de seguridad internacional}

Autoridades e internacionalistas brasileños han desplegado a lo largo de décadas un sistemático esfuerzo en la formulación e implementación de una política externa ejemplar, constructiva y sofisticada - tanto en términos globales, como hemisféricos o regionales. Tratase de la política externa de una potencia media con inclinaciones pacíficas, cooperativas y en gran medida solidarias, aunque naturalmente eficaz en la promoción de sus múltiples intereses nacionales. Más aún, Brasil es una potencia media que ofrece a sus vecinos - próximos y distantes - una serie de bienes públicos de gran relevancia y en gran medida insustituibles, entre otros: valores, mediaciones creíbles y moderación de conductas. En términos resumidos se trata de la inserción internacional de una potencia media que tradicionalmente ha favorecido el diálogo, la integración, el respeto por el derecho internacional, y un enfoque grociano de la política internacional (CERVO, 2002). Algo, sin duda, muy importante, sobretodo en un contexto global tan conturbado como el predominante en la primera década del siglo XXI (ROETT, 2003). Para los 
fines del presente artículo es importante evaluar las consecuencias generales y para el Gran Caribe derivadas del proyecto sudamericano brasileño, así como ciertos tópicos de seguridad internacional de interés específico.

\section{El proyecto estratégico sudamericano del Brasil y sus críticos}

A partir de 1993, durante la primera gestión del Embajador Celso Amorim como canciller, el discurso político-diplomático y estratégico brasileño ha pasado a privilegiar su identidad y circunstancia específicamente geográfica en lo concerniente a buena parte de su política regional. Naturalmente, el Brasil es un país sudamericano, condición que comparte con otros 10 Estados de la región. Aunque autoridades e internacionalistas reconocen que la identidad del país incluye otras dimensiones - tales como tratarse de un país occidental, en desarrollo, americano, amazónico, platino, mercosurino, etc. -, es cada vez más frecuente observar el entusiasmo de la elite diplomática brasileña por su dimensión geográfica y las consecuencias de ello derivadas en lo concerniente a su inserción internacional y geopolítica. Talvez la más reciente iniciativa en esta línea haya sido la creación, en diciembre de 2004, de la Comunidad Sudamericana de Naciones (CASA), después de intensas actividades de diplomáticos brasileños y de otros países - en abril de 2007, este foro regional fue redefinido con el nombre de Unión Sudamericana de Naciones (UNASUR).

Conviene reconocer, inicialmente, que todo país tiene la necesidad - y obligación - de considerar su circunstancia geográfica, especialmente en los procesos de formulación e implementación de las políticas regionales y globales. Así, Celso Lafer (2002) comenta, por ejemplo, que la América del Sur es parte constitutiva del "yo diplomático" brasileńo. Con efecto, el foco en América del Sur se fundamenta en lógicas, circunstancias y constataciones bastante obvias para las autoridades e internacionalistas brasileńos. Acontece que en el subsistema específicamente sudamericano seria el Brasil la potencia predominante. Este sería el escenario donde resaltarían más visiblemente las perspectivas y capacidades económicas, político-militares y, en menor medida, simbólico-culturales brasileñas.

Paralelamente, beneficios adicionales para la principal potencia 
sudamericana podrían ser identificados tanto en el ámbito doméstico como global, sobretodo en términos de prestigio, influencia, eficiencia económica y credibilidad. La organización de sendas reuniones entre países sudamericanos y sus contrapartes árabes (en 2005) y africanas (en 2006), junto con proyectos semejantes para el futuro con otros grupos de países, dicen mucho de la creciente capacidad de convocatoria global de Brasil que es el principal actor patrocinador de tales iniciativas. Argumentase que estas y otras iniciativas semejantes fortalecen las credenciales brasileñas tanto regionales como globales.

El proyecto sudamericano brasileño es resultado, entonces, de una línea de pensamiento geopolítico bien fundamentado, sofisticado $y$, hasta el momento, implementado de forma positiva para este país y, quizás, para sus vecinos y socios. Consecuentemente, el proyecto estratégico sudamericano del Brasil es una realidad e implica importantes desafíos tanto para el propio país como para vecinos, socios y eventuales competidores. Conviene reiterar que afortunadamente el proyecto brasileño es consecuente con su tradición pacífica, cooperativa, multilateral y talvez grociana. La búsqueda del liderazgo no implica, en modo alguno, apelo hobbesiano-expansionista-militarista, hipótesis que lo tornaría definitivamente inaceptable e impresentable dentro y fuera del país. En otras palabras, el proyecto brasileño de liderazgo sudamericano se fundamentaría en la hegemonía suave y la emergencia pacífica, lo que es -obviamente- cualidad altamente significativa en un mundo ya suficientemente conturbado y amenazado por pretensiones de potencias claramente imperialistas (SANTOS, 2005). Así, es importante constatar que la presunción de liderazgo brasileño en Sudamérica -por veces precipitadamente considerado natural y legitimo- tiene adeptos y simpatizantes tanto dentro como fuera del país, por cuenta de su potencial moderador y estabilizador. Recuérdese que se trata de una potencia media con reconocido poder de convocatoria, con importantes recursos económicos y financieros, y una creciente sensibilidad político-diplomática.

En una región históricamente polarizada por el binomio monroísmobolivarianismo, la alternativa brasileña implica el surgimiento de un paradigma nuevo y altamente significativo. Entre sus puntos fuertes se destaca su pragmatismo, inclusive en lo concerniente a su opción por privilegiar 
proyectos conjuntos de infraestructura económica. También su carácter no amenazador ni violento. Consecuentemente se trataría de una propuesta de hegemonía suave -aunque normalmente no es presentada como tal por las autoridades brasileńas. Falta, entretanto, terminar de convencer a la mayoría de los hasta ahora poco interesados vecinos sobre sus bondades. Brasil precisaría ser mucho más generoso y luchar contra no pocas suspicacias y desafíos. Todo ello sin olvidar que la emergencia del Brasil como gran potencia mundial del siglo XXI no podrá ser alcanzada a costas o en desmedro de sus vecinos más inmediatos o más distantes.

\section{Brasil y los países de la cuenca del Caribe frente a los desafíos de la seguridad regional, hemisférica y global}

Brasil y los países del gran Caribe están sujetos a una serie de presiones endógenas y exógenas que tienen un impacto directo - e indirecto - en sus respectivas inserciones internacionales de seguridad, sea en nivel global, hemisférico, regional, nacional o comunitario-individual. Cada país, en función de sus trayectorias y circunstancias específicas, tiende a identificar y valorizar ciertas amenazas, desafíos y oportunidades, tanto tradicionales o wesfelianas como emergentes o pos-wesfelianas. También, es importante recordar que América Latina y el Caribe, en general, es una región con bajos gastos militares, con predominio de regimenes democráticos de gobierno, con complejas redes de integración e interdependencia y con poquísimas hipótesis de conflicto militar interestatal. Existen, entretanto, ciertas amenazas, desafíos y oportunidades de cooperación en materia de seguridad internacional vinculados, por ejemplo, a la dimensión internacional del conflicto armado colombiano, a los ilícitos transnacionales, al fenómeno del terrorismo globalizado - sobretodo después de los acontecimientos de $11 \mathrm{de}$ septiembre de 2001 y eventos subsecuentes.

No es objeto de éste artículo repasar tales temáticas de seguridad global, hemisférica y nacional, incluso porque existe harta literatura especializada al respecto (DAVID, 2001). Si interesa, en cambio, identificar y reflexionar sobre algunas prioridades de seguridad internacional - en el sentido amplio del término - que atañen a una emergente agenda específicamente brasileñocaribeña. 
Al estudiar las interpretaciones de especialistas brasileños - civiles y militares - sobre las relaciones de seguridad con sus vecinos del norte es posible identificar lo que -a falta de mejores definiciones - podría denominarse como Caribe próximo y Caribe distante. Siendo que el Caribe próximo incluiría lo que corresponde a las relaciones brasileñas de seguridad con sus cuatro vecinos caribeños de la frontera norte: Colombia, Guyana, Surinam y Venezuela - además del peculiar caso de la Guyana Francesa. Quiere decir, los países de la subregión norte de América del Sur. Al mismo tiempo, el Caribe distante incluiría a todos los otros países (y territorios coloniales) que forman parte de la cuenca del Caribe: México, las Antillas, Centroamérica, etc. Naturalmente, las amenazas, los desafíos y las oportunidades de seguridad internacional percibidas por las autoridades brasileñas en el Caribe próximo son mucho más sensibles que sus contrapartes en el Caribe distante - debido a sus consecuencias directas e inmediatas en la seguridad y defensa nacional brasileña (ALMINO, 2002).

Las principales amenazas, desafíos y oportunidades de seguridad percibidos por analistas brasileños en el Caribe próximo incluyen fundamentalmente: la cuestión amazónica, las consecuencias internacionales del conflicto colombiano y el virtual surgimiento de una nueva carrera armamentista sudamericana (BONILLA, CEPIK, 2004).

En relación a la así llamada cuestión amazónica es importante recordar inicialmente que la mitad del territorio brasileño forma parte de la cuenca del río Amazonas. Consecuentemente, Brasil es un país con identidad amazónica, característica que comparte con Bolivia, Colombia, Ecuador, Guyana, Perú, Surinam y Venezuela. Obsérvese que los ocho países son miembros de la Organización del Tratado de Cooperación Amazónica (OTCA).

En lo concerniente específicamente a los temas de seguridad internacional en la región amazónica, los desafíos están vinculados a la seguridad ambiental (destrucción de la mayor selva tropical húmeda del planeta), a la seguridad sociocultural de las comunidades indígenas residentes en la región y de seguridad político-jurídica. Esta última asociada a una tenue estatalidad, que favorece el surgimiento de altos índices de violencia social, la presencia del crimen organizado transnacional y delitos conexos, la explotación irracional de los recursos naturales y el surgimiento de lo que algunos analistas brasileños 
llaman de virtual Estado paralelo en la región. Súmase a esto una serie de críticas de actores transnacionales de seguridad -tales como organizaciones no gubernamentales, instituciones religiosas, organizaciones de defensa de los derechos humanos, etc. - y de ciertas potencias extra-regionales, denunciado la falta de control, la incapacidad y la desidia de las diferentes autoridades nacionales frente a la destrucción de una región vital en términos de seguridad ambiental global, hemisférica y nacional.

La reacción de los gobiernos frente a la cuestión amazónica ha evolucionado de forma positiva. Actualmente la política brasileña y de otros países vecinos con relación a la cuestión amazónica incluye una mayor coordinación entre los miembros de la Organización del Tratado de Cooperación Amazónica bajo la perspectiva de la seguridad ambiental y del desarrollo sustentable. En segunda instancia se propone ampliar la estatalidad por medio de infraestructura social, económica y política. Y, en tercer lugar, reforzar concertadamente las respectivas presencias militares y policiales, con objetos de cohibir y reprimir delitos transnacionales y mejorar la vigilancia y protección estratégica de la región -en tal sentido, el gobierno brasileño creó el Sistema de Vigilância da Amazônia (BRIGAGÃO, 2002).

El conflicto armado colombiano es, sin duda alguna, un importantísimo desafío de seguridad internacional para el Brasil y países vecinos. Dicho conflicto involucra diferentes actores y dimensiones. Entre ellos vale destacar las fuerzas militares y policiales del Estado - bastante fortalecidas durante el gobierno del presidente Álvaro Uribe -, las fuerzas guerrilleras (Fuerzas Armadas Revolucionarias de Colombia y Ejercito de Liberación Nacional), los carteles de narcotraficantes, las milicias paramilitares, el creciente número de desplazados y refugiados, bien como la influencia de potencias externas con vínculos e intereses en dicho conflicto tales como los Estados Unidos (y su Plan Colombia), Venezuela, Cuba, Ecuador y Panamá, además del propio Brasil.

Conviene agregar que la posición básica del gobierno brasileño ante el conflicto colombiano es de prudencia, moderación, neutralidad, disuasión activa y bajo perfil, todo ello inspirado en el principio de la no intervención en los asuntos políticos internos de otros Estados. En años recientes, el gobierno brasileño autorizó la exportación de armamento para el gobierno 
colombiano, entretanto, se niega a reconocer a las FARC como grupo terrorista o narcotraficante -a pesar de que en 2001 un conocido y peligroso narcotraficante brasileño, Luiz Fernando da Costa, fue capturado junto con militantes de las FARC, demostrando que la hipótesis de narcoactividad de dicho grupo insurgente tiene cierta credibilidad, y reconociendo además las repercusiones negativas que el narcotráfico provoca en la sociedad brasileña (crimen, violencia, corrupción). Aparentemente, la actual neutralidad brasileña frente al conflicto armado interno colombiano lo facultaría como eventual mediador en un futuro proceso negociador orientado a alcanzar un acuerdo general de paz entre las partes.

Paralelamente, los programas de modernización de las fuerzas armadas iniciado por Chile, y acompańado por Colombia y Venezuela, han provocado no poca preocupación y ansiedad en Brasilia debido al virtual surgimiento de una nueva y costosa carrera armamentista en Sudamérica -aunque normalmente no es presentada como tal por las autoridades de tales países. Dicho desafío es importante para las autoridades brasileñas dado que podría modificar el tradicional equilibrio militar de la región y cuestionar el mito de la superioridad estratégico-militar brasileña en Sudamérica.

La adquisición de una nueva generación de armamento tecnológicamente sofisticado puede, también, revitalizar antiguas reivindicaciones y disputas fronterizas. Difícilmente el Brasil acompañará pasivamente tales tendencias. Todo ello podrá provocar efectos perniciosos y escepticismo en materia de fomento de medidas de confianza, control de armamento, desarme, seguridad cooperativa, integración militar, además de desviar los escasos recursos estatales hacia finalidades poco productivas o constructivas -recordando que los países de la región tienen importantes tareas pendientes en materia de desarrollo humano.

En lo concerniente al Caribe distante, una eventual agenda de seguridad internacional de interés tanto de brasileños como de caribeños podría incluir los siguientes tópicos específicos: la represión conjunta y multilateral de ilícitos transnacionales (narcotráfico, tráfico de armas, tráfico de personas, reciclaje de activos, y otros delitos conexos); la no proliferación de armamentos de destrucción en masa (nuclear, biológica, química y vectores); la prevención del terrorismo; la activa participación conjunta en misiones de 
paz -ejemplo de ello es la Misión de Estabilización de las Naciones Unidas en Haití (MINUSTAH), comandada por militares brasileños e integrada por contingentes militares y policiales procedentes de más de 30 países - ; la reconfiguración y desmilitarización de las instituciones y de las doctrinas de seguridad hemisférica; la difusión de las nuevas concepciones de seguridad internacional; la transparencia en gastos, políticas y doctrinas militares; la cooperación militar Brasil-Gran Caribe; la reanudación controlada y responsable de las transferencias de material de empleo militar y policial de fabricación brasileña para países del Caribe; la oposición frente a políticas unilateralistas e intervencionistas de las grandes potencias; entre otros. En tal hipótesis, una eventual agenda brasileño-caribeña de seguridad se erigiría en ejemplo positivo cooperación internacional.

\section{Consideraciones finales: tres escenarios prospectivos para el futuro de las relaciones entre Brasil y los países de la cuenca del Caribe (2008-2018)}

¿Cuáles son las perspectivas para el futuro de las relaciones Brasil-Gran Caribe? Aunque no exista una respuesta completa ni definitiva para esta pregunta, si es posible identificar algunos escenarios plausibles. Naturalmente, el curso final de la relación brasileño-gran caribeña dependerá tanto de las presiones y transformaciones globales, hemisféricas y transnacionales, como de las opciones de política internacional de los gobiernos y de los actores no gubernamentales de los países en cuestión -así como de actores procedentes de países extra-regionales con vínculos e intereses tanto en la cuenca del Caribe como en Brasil.

Llevando en consideración el espacio temporal del próximo decenio se hace posible imaginar tres grandes escenarios para las relaciones en cuestión. Tales escenarios podrían ser denominados de: (a) inercial, (b) optimista, y (c) pesimista.

En el escenario inercial la relación brasileño-gran caribeña continuaría siendo dominada por las regularidades económicas, políticas y de seguridad observadas en los últimos años. En el campo económico, el comercio entre las partes continuaría siendo bastante significativo, pero el perturbador déficit de la mayoría de los países caribeños con relación al Brasil terminaría 
impulsando ciertas medidas restrictivas y proteccionistas. Consecuentemente, las relaciones económicas tenderían a estabilizarse y eventualmente a declinar. En el campo político y de seguridad, las relaciones seguirían siendo, en general, positivas, aunque con pocos resultados realmente satisfactorios para las partes. Los temas de interés común podrían ser tratados en foros multilaterales más amplios, tales como el Grupo de Rio, la Comunidad Iberoamericana de Naciones, la Organización de los Estados Americanos, o la Organización de las Naciones Unidas. En tal sentido, Brasil continuaría siendo un actor amistoso pero modesto en la cuenca del Caribe.

En el escenario optimista existiría una sensible aproximación de los vínculos económicos, políticos y de seguridad internacional. El creciente superávit comercial brasileño sería compensado con sistemáticas inversiones de capitales privados brasileños en países caribeños, con transferencia de tecnología, con real apertura del mercado brasileño para las exportaciones caribeñas, con incremento de la cooperación técnica horizontal, y con otras iniciativas compensatorias. Algunos países caribeños podrían aproximarse del MERCOSUR (Venezuela, Colombia, Cuba, México, Nicaragua, Guyana, Surinam, y Trinidad y Tobago). En el campo político y de seguridad, el diálogo entre las partes alcanzaría un elevado grado de intensidad. Brasil pasaría a ser un actor extra-regional relevante en el Caribe, siguiendo el patrón implementado por otras potencias semejantes tales como Espańa, Chile, Francia, Canadá o Japón. Una mediación brasileña que permitiese el fin de las hostilidades y la pacificación de Colombia sería plausible. Una aproximación entre Washington y Caracas-La Habana, con apoyo políticodiplomático brasileño, sería otra excelente alternativa. Sin olvidar el urgente y necesario control de la cuestión amazónica en todas sus dimensiones.

En el escenario pesimista las relaciones económicas y específicamente comerciales sufrirían una rápida declinación, por cuanto los productos y servicios brasileños podrían ser substituidos por contrapartes de otros países más accesibles y comprensivos. El proyecto geopolítico sudamericano del Brasil no solamente terminaría fracasando, como debilitaría mucho la credibilidad de su política regional -generando un eventual aislamiento con relación a países vecinos. Anacrónicas y veleidosas pretensiones hegemónicas podrían resurgir con desastrosas consecuencias para la mayoría de los pueblos 
en cuestión, aunque en beneficio algunos pocos. Claramente se trataría de una situación con pocas posibilidades para el diálogo, para la cooperación y para la necesaria solidaridad entre las partes.

Cree el autor de este artículo que las relaciones entre Brasil y los países del Caribe terminará avanzando por algún punto intermedio entre los escenarios inercial y optimista. En tal hipótesis, se trataría de un escenario con moderado optimismo. El mismo permitiría trabajar con una agenda fundamentada tanto en el pragmatismo, como en las afinidades electivas, en la sensibilidad, en la solidaridad y en la comunidad de intereses y valores. En el marco de las dramáticas transformaciones globales y hemisféricas vigentes en los primeros años del XXI, tal escenario implicaría alcanzar el objetivo de establecer relaciones maduras, sólidas, constructivas y mutuamente beneficiosas para brasileños y caribeños. 


\section{Referencias Bibliográficas}

ALMINO, João. Inserção internacional de segurança do Brasil: a perspectiva diplomática. In: BRIGAGÃO, Clóvis; PROENÇA JÚNIOR, Domício (Orgs). Brasil e o mundo. Novas Visóes. Rio de Janeiro: Francisco Alves Editora, 2002, p. 27-85.

BONILLA, Adrián; CEPIK, Marco. Seguridad andino-brasileña: conceptos, actores y debates. In: CEPIK, Marco; RAMÍREZ, Socorro. (Ed.). Agenda de seguridad andino-brasileña/primeras aproximaciones. Bogotá: FESCOL, 2004, p. 41-94.

BRIGAGÃO, Clóvis. SIVAM: environmental and security monitoring in Amazônia. In: TULCHIN, Joseph S.; GOLDING, Heather A. (Eds.). Environment and security in the Amazon basin. Washington: WWIC, 2002, p. $115-130$.

BURNS, E. Bradford. A Aliança não escrita. O Barão do Rio Branco e as relaçóes Brasil-Estados Unidos. Rio de Janeiro: EMC, 2003.

CEPAL. Globalización y desarrollo. Santiago de Chile: ONU, 2002.

CERVO, Amado Luiz. A dimensão da segurança na política exterior do Brasil. In: BRIGAGÃO, Clóvis; PROENÇA JÚNIOR, Domício. (Orgs.). Brasil e o mundo. Novas visóes. Rio de Janeiro: Francisco Alves Editora, 2002, p. 319-361.

DAVID, Charles-Philippe. A guerra e a paz. Abordagens contemporâneas da segurança e da estratégia. Lisboa: Instituto Piaget, 2001.

DOMÍNGUEZ AVILA, Carlos. Brasil-Centroamérica: cien años de solidaridad y cooperación (1906-2006). Cuadernos Americanos, ańo XX, v. 4, n. 118, p. 125-143, 2006.

FERNÁNDEZ, Rafael; LIMA, Maria Regina Soares de. Las aspiraciones internacionales de Brasil y de México. In: MENA, Antonio Ortiz; AMORIM NETO, Octavio; CASTRO, Rafael Fernández de (Ed.). Brasil y México: encuentros y desencuentros. México: SRE, 2005, p. 111-166. 
HELD, David. et al. Global transformations. Stanford: Stanford University Press, 1999.

LAFER, Celso. La identidad internacional de Brasil. Buenos Aires: FCE, 2002.

ROETT, Riordan. El papel de Brasil como potencia regional. In: PAZ, Guadalupe; ROETT Riordan (Comp.). América Latina en un entorno global en proceso de cambio. Buenos Aires: GEL, 2003, p. 227-246.

SANTOS, Luís. A América do Sul no discurso diplomático brasileiro. Revista Brasileira de Politica Internacional, v. 48, n. 2, p. 185-204, 2005.

TICKNER, Arlene. Política internacional y crisis interna: Colombia, Estados Unidos y los países vecinos. In: TULCHIN, Joseph; MANAUS, Raúl Benítez; DIAMINT, Rut (Eds.). El rompecabezas. Conformando la seguridad hemisférica en el siglo XXI. Buenos Aires: Bononiae Libris, 2006, p. 427448 . 